\title{
Adding a Water-Repellent Barrier to Low-Cost or Home-Made Masks and Respirators Using Aerosols that Protect Clothing and Furniture from Spills and Liquids
}

\author{
Mark Zilberman, M.Sc., \\ Shiny World Corporation (Canada)
}

\begin{abstract}
In connection with the COVID-19 pandemic in the spring of 2020, an unprecedented situation has developed with masks and respirators protecting respiratory organs. The purpose of the mask (respirator) is to protect the person from drops of liquid that the COVID-19 carrier spreads around themselves when coughing/sneezing. Unfortunately, low-cost, non-professional and home-made masks and respirators let in a significant amount of droplets. An ideal solution would be to treat a cheap or even a makeshift mask or respirator to make it water-repellent (like a rubber respirator), but to still allow the wearer of the mask the ability to breathe and talk freely. Fortunately, this dilemma was long and successfully solved by manufacturers of products to protect clothes and furniture from spills and liquids.

This article describes experiments that tested the "Tana ${ }^{\circledR}$ Style $16 \AA$ Protector" aerosol manufactured by JOHNSON \& SON, INC for the installation of a water-repellent barrier on household water-permeable respirators and cotton fabric. The methodology and photographs of the passage of a jet of water through a household mask and cotton fabric are given before and after "Tana ${ }^{\circledR}$ Style 16® Protector" aerosol treatment. Aerosols have been shown to be highly effective for installing a water-repellent barrier on water-permeable respirators and cotton fabric. It is understood that other countries may have similar aerosols under different names. The breathing through a waterrepellent barrier, as well as possible long-term effects, are discussed.
\end{abstract}

Keywords: COVID-19, pandemic, mask, respirator, aerosol, waterproof, water-repellent

In connection with the COVID-19 pandemic in the spring of 2020, an unprecedented situation has developed with masks that protect the respiratory system from a coughing and sneezing. The shortage, and lack of professional masks and respirators, led to the production of home-made and/or unprofessional masks that did not pass any testing. The general approach is " a home-made mask is better than none".

From the point of view of doctors, the goal of the mask (respirator) is to protect people from drops of liquid that the COVID-19 carrier spreads around itself when coughing or sneezing.

From the point of view of an individual wearing a mask (respirator), the goal of the mask (respirator) is to protect the wearer from the drops of liquid that other people circulate around them.

Both of these goals are achieved only if the mask (respirator) does not pass liquid droplets of small size. Unfortunately, regular professional and especially non-professional masks (respirators) pass a certain amount of liquid. Only high-quality professional respirators made of rubber or plastic truly shield fluid droplets. However, they are expensive (more than \$100), they are much more difficult to manufacture, they are few, and accordingly they were quickly sold out and ceased to be available to ordinary customers.

Therefore, the ideal solution would be to treat a cheap or even home-made mask to make it waterrepellent (to function like a rubber respirator), but at the same time to allow the wearer of the mask 
to breathe and talk freely. It would seem that this indescribable task was long and successfully solved by manufacturers of products that protect clothing and furniture from spills and liquids. Companies such as "3M" [1], "S.C. JOHNSON \& SON, INC "[2] and others have long produced aerosols, which, after settling on the fabric, make it water-repellent and, at the same time, let air through. These two companies are popular in the USA and Canada. It is understood that other countries may have similar aerosols under different names.

The author of the article did the experiments presented in this article to test the effectiveness of these products on cheap water-permeable respirators and cotton fabric.

\section{Un-treated materials}

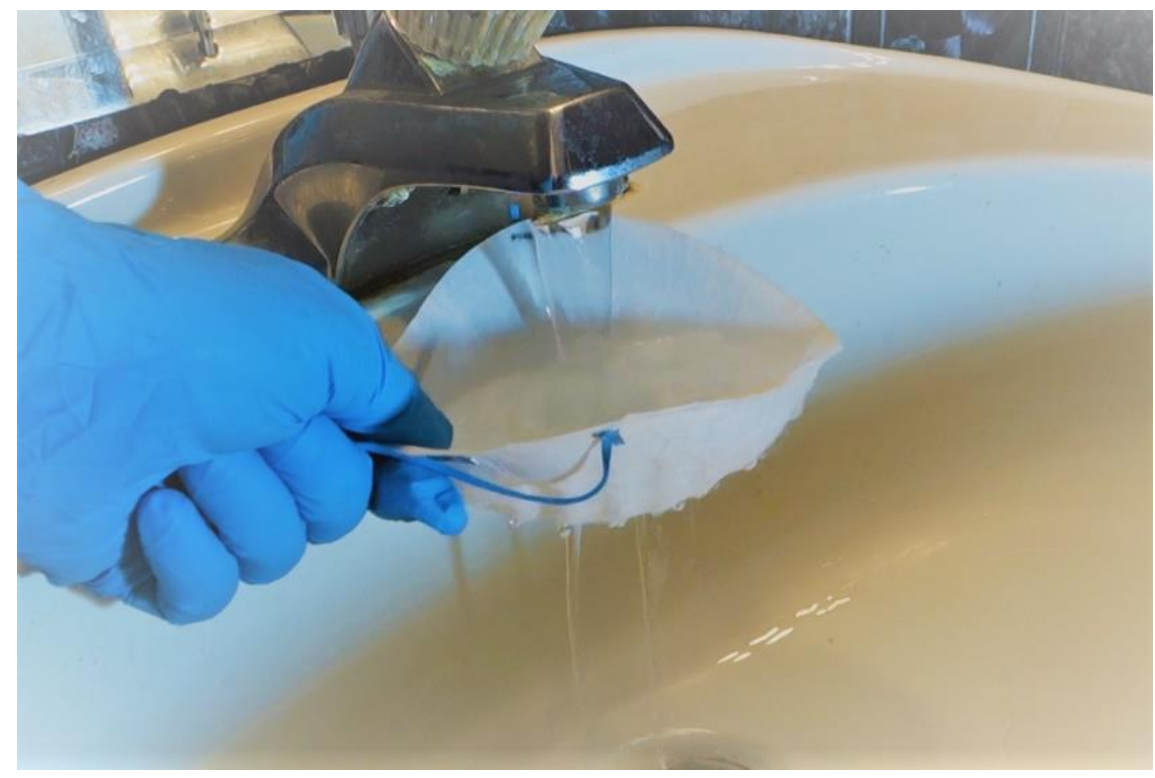

Photo (1)

Photo (1) illustrates the passage of water through an un-treated household respirator.

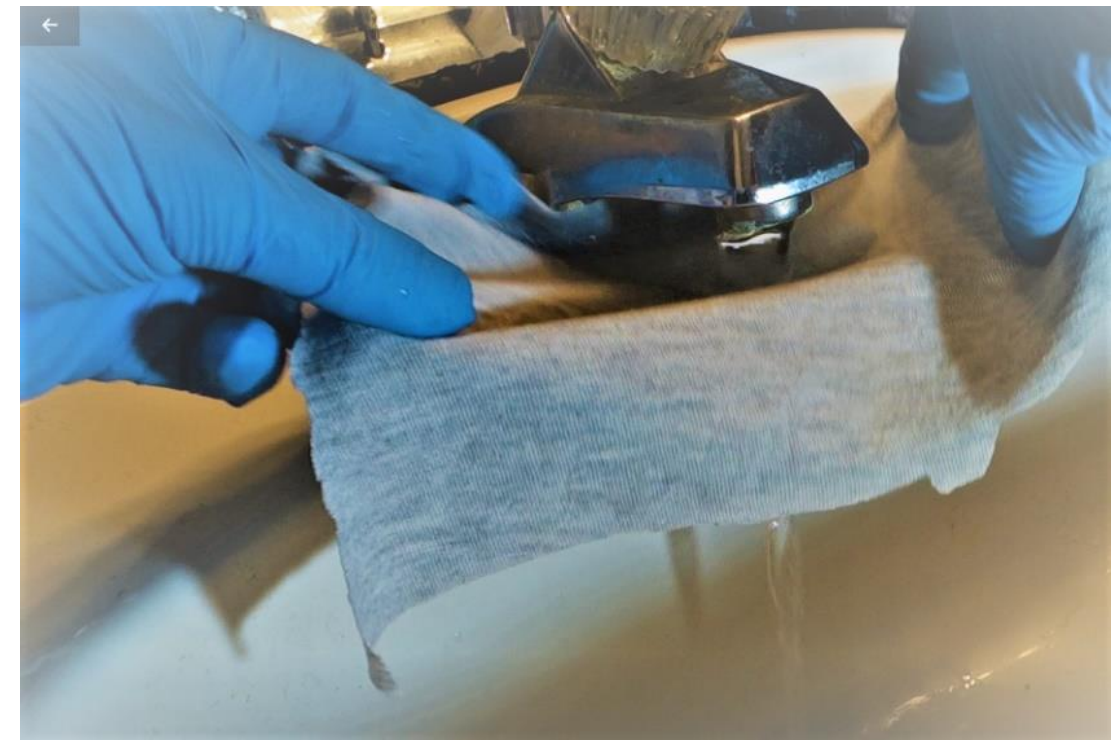

Photo (2) 
Photo (2) illustrates the passage of water through un-treated cotton fabric.

It can be seen that fabric as well as cheap household respirator let water pass through easily.

\section{Treatment}

As a treating agent, the spray "Tana ${ }^{\circledR}$ Style $16 \circledR$ Protector" manufactured by JOHNSON \& SON, INC. was used. The outer surface of the household moisture-permeable respirator (as well as the cotton fabric) was treated from an aerosol can for 10 seconds from a distance of 20-25 centimeters (as recommended by the "Tana® Style 16® Protector"). After that, the material was dried for 15 minutes and then treated with "Tana ${ }^{\circledR}$ Style $16 ®$ Protector" one more time.

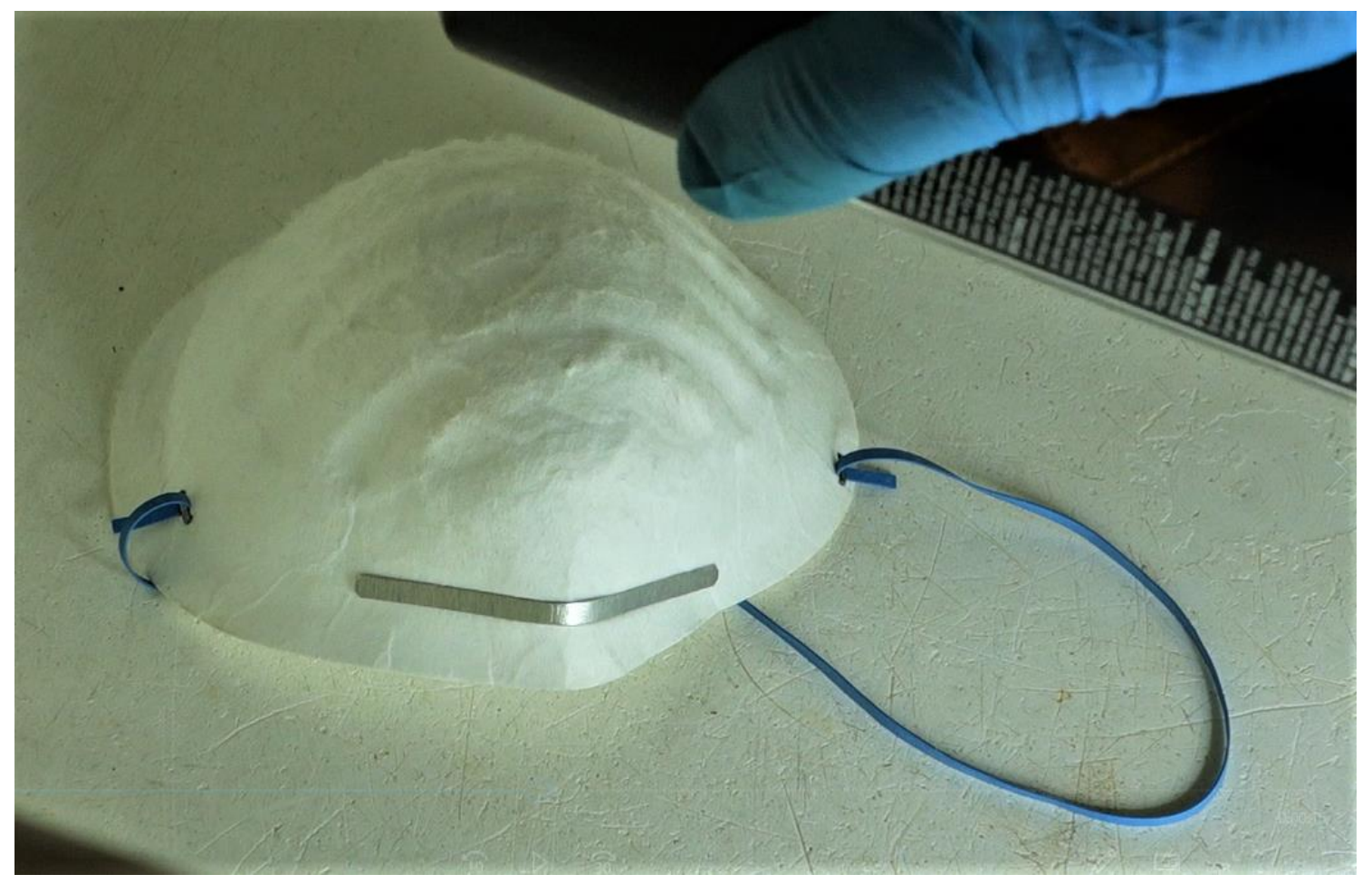

\section{Photo (3)}

Photo (3) illustrates the treatment of a household liquid-permeable respirator using a "Tana® Style 16® Protector" aerosol can.

\section{Result of treatment}

Photos (4) and (5) illustrate the absence of water passing through a treated household waterpermeable respirator. Despite the fact that only the external side of the respirator was treated, water stopped passing through it. 


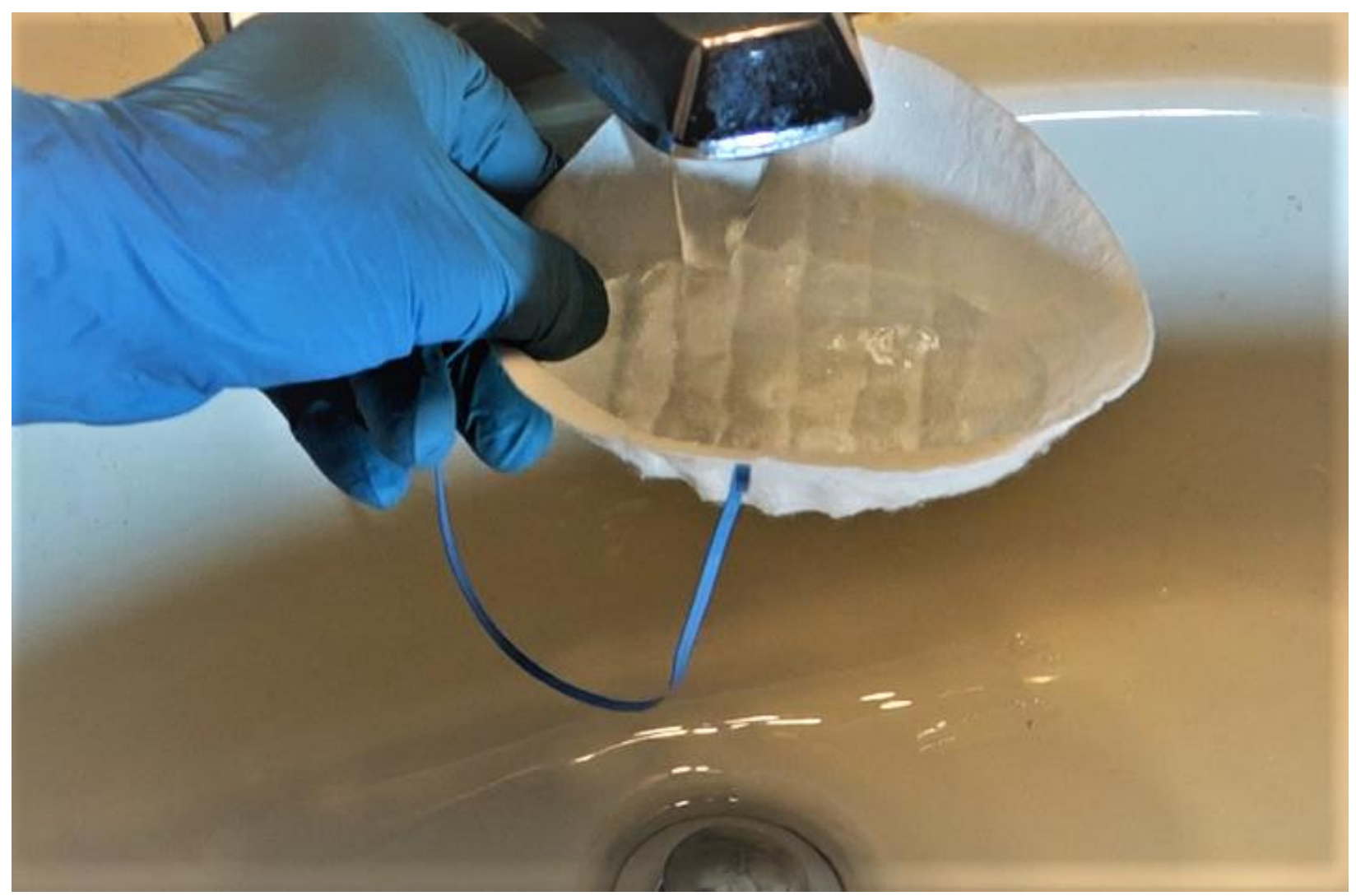

Photo (4)

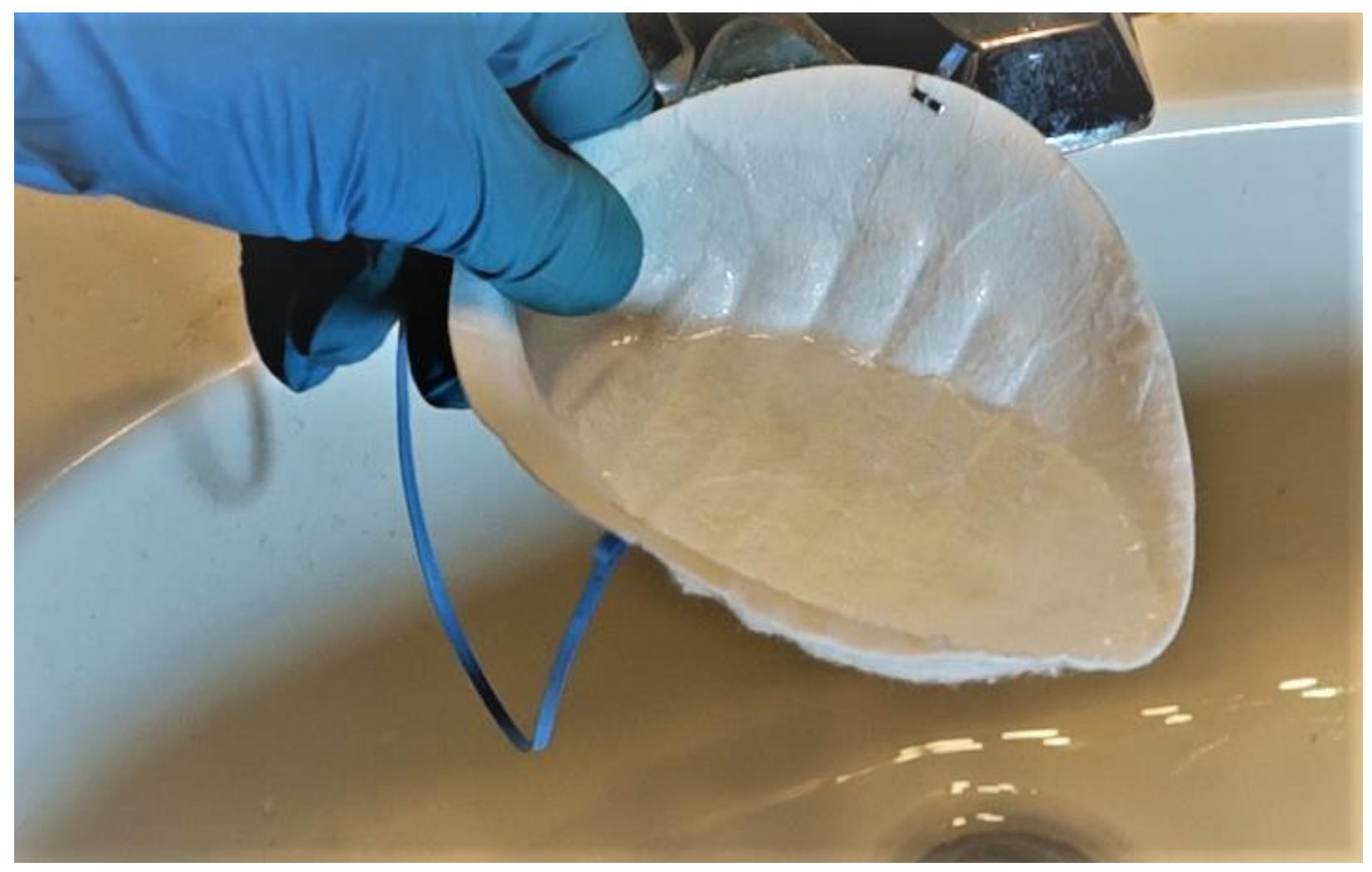

Photo (5) 
The same result was tested on treated cotton fabric. Photos (6) and (7) illustrate the absence of water passing through the treated cotton fabric.

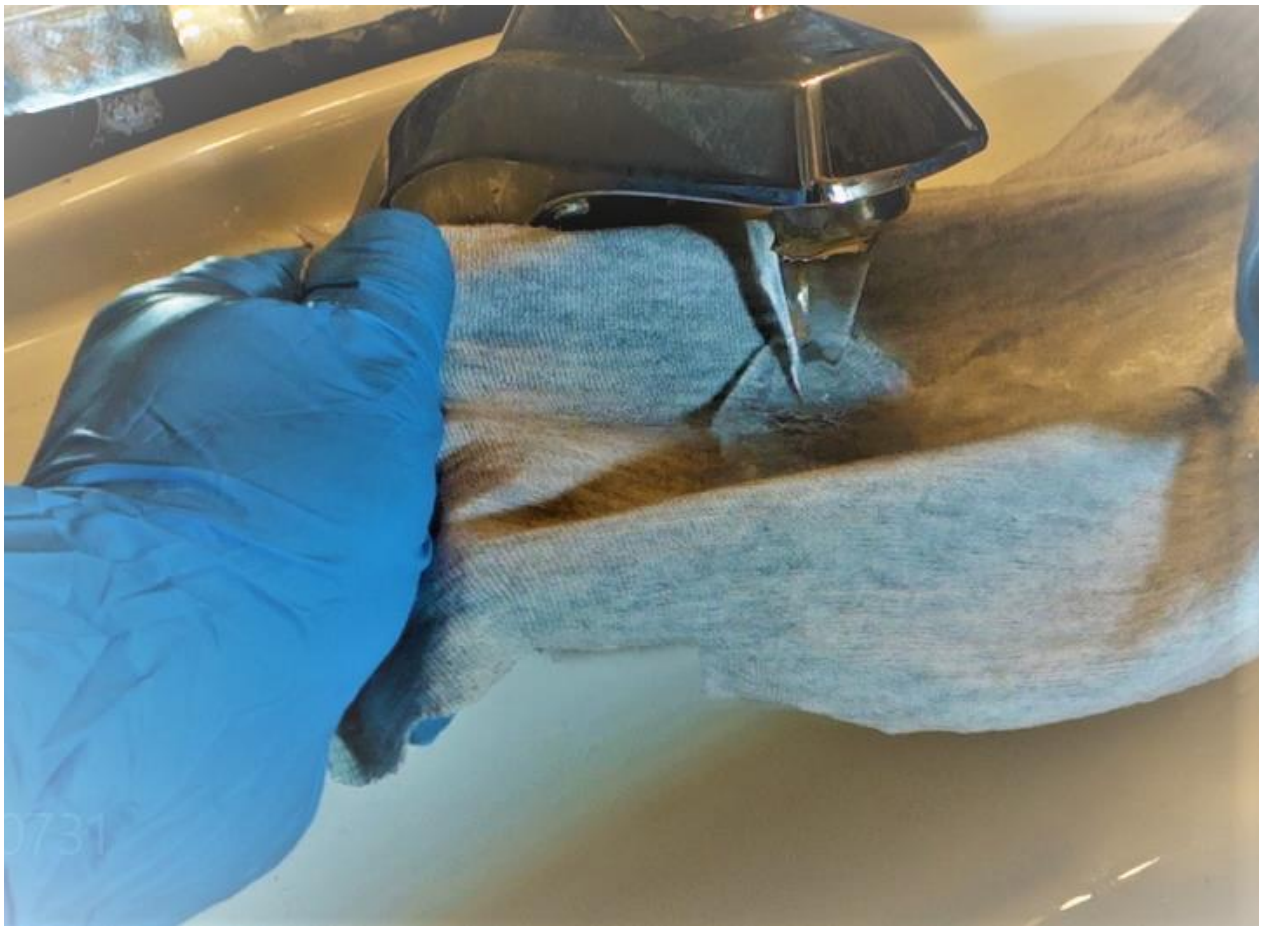

Photo (6)

In the photograph (7) it is seen how water spills over the edge of the fabric but does not pass through the fabric itself.

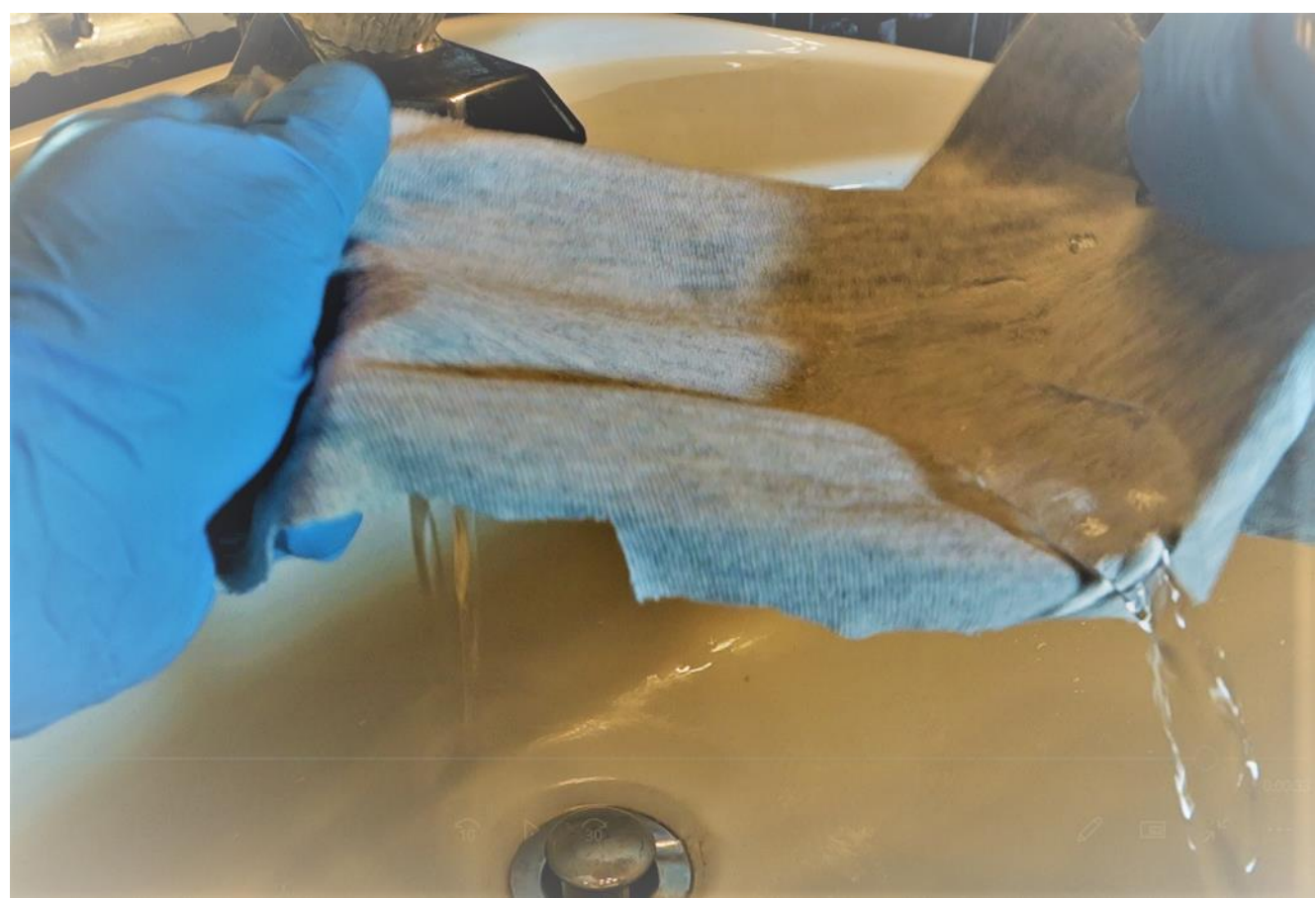

Photo (7) 


\section{Discussion}

1. The purpose of treatment of the mask (respirator) is not protection against the COVID-19 virus. Since air passes through the material both before and after processing, the virus can also pass through it. But it will only pass if it "hangs" in the air as an aerosol. And in this case, its concentration is small and at the moment there is no evidence that the aerosol infection of COVID19 can lead to illness.

The aim of the treatment is to significantly improve the protection of cheap / homemade masks and respirators from the penetration of drops of cough or saliva, which can carry COVID-19 in a pathogenic concentration.

2. Does the treated material have enough air to breathe? To answer this question, the author spent several hours in a treated respirator indoors and outdoors. No problems with a lack of air were noted. The author also did not note condensation of moisture contained in the exhaled air on the inner surface of the treated respirator. It seems that moisture came out with the air, and at the same time did not settle on the walls of the respirator.

3. After processing, the material retains the smell of the "Tana ${ }^{\circledR}$ Style 16 ${ }^{\circledR}$ Protector" aerosol for approximately one day. It is not recommended to use a treated respirator / mask before this time, so that the "Tana ${ }^{\circledR}$ Style $16 ®$ Protector" aerosol molecules do not enter the lungs.

4. At the moment, there is no data on the long-term effect of breathing through the treated tissue. However, no one can guarantee that breathing through aerosol-treated material is harmless. Potentially, it can lead to diseases of the respiratory tract and / or lungs. Research of the long-term effects must be done by the health professionals and is out of the author's competency. However, choosing between the potential unexplored danger and the actual significant protection of homemade masks from the penetration of liquid droplets - everyone makes the choice himself.

\section{Conclusion}

After reading the article, the idea of adding a water-repellent barrier on cheap or home-made masks and respirators by spraying them with aerosols that protect clothing and furniture from spills and liquids seems self-evident. Therefore, it would be appropriate to quote the parable of the Egg of Columbus [3]

An egg of Columbus or Columbus' egg (Italian: uovo di Colombo ['wo'vo di ko 'lombo]) refers to an idea or discovery that seems simple or easy after the fact. The expression refers to an apocryphal story, dating from at least the 15th century, in which it is said that Christopher Columbus, having been told that finding a new trade route was inevitable and no great accomplishment, challenges his critics to make an egg stand on its tip. After his challengers give up, Columbus does it himself by tapping the egg on the table to flatten its tip.

The story is often alluded to when discussing creativity. ... It also shows that anything can be done by anyone with the right set of skills; however, not everyone knows how to do it.

\section{References}

1. https://www.scotchgard.com/3M/en_CA/scotchgard-ca/how-to-use-fabric-upholsteryprotector/ 
2. https://www.tana.com/en-ca/products/tana-style-16-protector

3. https://en.wikipedia.org/wiki/Egg_of_Columbus 